\title{
Percepções de professoras sobre o uso pedagógico de Tecnologias Emergentes: uma investigação em Porto Velho/RO
}

\author{
Teachers perceptions on the pedagogical use of emerging \\ technologies: an investigation in Porto Velho/RO
}

\section{Percepciones de profesores sobre el uso pedagógico de tecnologías emergentes: una investigación en Porto Velho/RO}

Delziana Oliveira ${ }^{1}$; Rafael Fonseca de Castro²; Rosângela de Fátima Cavalcante França $^{3}$

\section{RESUMO}

O presente artigo, recorte de uma pesquisa de Mestrado, objetiva investigar percepções de professoras de escolas públicas de Porto Velho, Rondônia, quanto ao uso das Tecnologias Emergentes (TE) em suas práticas pedagógicas. Tratou-se de uma pesquisa qualitativa, do tipo Exploratória, realizada entre maio e setembro de 2018. Os dados foram coletados via entrevista semiestruturada, realizada com seis professoras de cada uma das duas escolas pesquisadas, e foi adotada a análise textual discursiva para suas análises. Verificou-se que as professoras da Escola A sentem-se mais preparadas para o uso pedagógico das TE do que as da Escola B. A partir de suas percepções, os achados indicam: que a maioria não reconhece a relação teoria-prática; um sentimento empírico de preparo para o uso das TE e; severos problemas estruturais nas escolas. Mediante tais resultados, infere-se que o uso das TE nas práticas pedagógicas dessas professoras apresenta limitações formativas e estruturais, reflexo de lacunas de formação e de limitações estruturais nas escolas públicas do município, dificultando a inserção de Tecnologias Emergentes típicas do século XXI, de forma atrativa aos educandos, em suas aulas.

Palavras-chave: Tecnologias emergentes; Prática pedagógica; Educação Básica; Amazônia Ocidental.

\footnotetext{
ABSTRACT

This article, an excerpt from a Master's research, aims to investigate the perceptions of teachers from public schools in Porto Velho, state of Rondônia, regarding the use of Emerging Technologies (ET) in their pedagogical practices. This was a qualitative study, an Exploratory one, conducted between May and September 2018. Data were collected through semi-structured interviews, carried out with six teachers from each of the two schools investigated, and discursive textual analysis was adopted for analysis. It was found that the teachers at School A feel more prepared for the pedagogical use of ET than those at School B. From their perceptions, the research findings point out: that most of them do not recognize the theory-practice relation; an empirical feeling of preparation for the use of ET and; severe structural problems in schools. Through such results, the use of ET in the pedagogical practices of these teachers has formative and structural limitations, reflecting gaps in teacher

${ }^{1}$ Mestre pelo Programa de Pós-Graduação em Educação (PPGE), Bolsista CAPES 2016-2018, Universidade Federal de Rondônia (UNIR). Secretaria Municipal de Educação. Porto Velho/RO - Brasil.

2 Doutor em Educação. Docente Permanente do Programa de Pós-Graduação em Educação (PPGE) e do Mestrado Profissional em Saúde da Família (PROFSAUDE), Universidade Federal de Rondônia (UNIR). Porto Velho/RO - Brasil.

3 Doutora em Educação. Docente Permanente do Programa de Pós-Graduação em Educação (PPGE), Universidade Federal de Rondônia (UNIR). Porto Velho/RO - Brasil.
} 
training and structural limitations at public schools in the city, making it difficult to insert Emerging Technologies typical from the 21st century, attractive to students, in their classes.

Keywords: Emerging Technologies; Pedagogical Practices; Basic Education; Western Amazon.

\section{RESUMEN}

Este artículo, un extracto de una investigación de Maestría, objetiva investigar las percepciones de maestras de escuelas públicas en Porto Velho, departamento de Rondônia, sobre el uso de las Tecnologías Emergentes (TE) en sus prácticas pedagógicas. Este fue una investigación cualitativa, un Estudio Exploratorio, realizada entre mayo y septiembre de 2018. Los datos se recogieron a través de entrevistas semiestructuradas, realizadas con seis profesores de cada una de las dos escuelas investigadas, y adoptada el análisis textual discursivo para su análisis. Se descubrió que las docentes de la Escuela A se sienten más preparadas para el uso pedagógico del TE que las de la Escuela B. Desde sus percepciones, los resultados señalan: que la mayoría de ellas no reconoce la relación teoría-práctica; un sentimiento empírico de preparación para el uso de ET y; graves problemas estructurales en las escuelas. Tales resultados reflejan brechas en la formación de las profesoras y la precaria estructura de las escuelas públicas de la ciudad, lo que dificulta la inserción de tecnologías emergentes típicas del siglo XXI, atractivo para los estudiantes, en sus clases.

Palabras clave: Tecnologías emergentes; Práctica pedagógica; Educación básica; Amazonia Occidental.

\section{INTRODUÇÃO}

Com a convergência entre tecnologias da informação e da comunicação, deu-se o entrelaçamento que culminou em uma espécie de hibridismo de tecnologias: computação, comunicação e digitalização, gerando as mais diversas formas e suportes à informação possíveis (textos, hipertextos, imagens, sons, vídeos etc.). A disseminação do acesso e do compartilhamento de informações foi expandida, sejam elas quais forem: textuais, visuais, sonoras ou multimídia (SANTAELLA, 2014).

Diante desse contexto de expansão informacional, a partir de uma revolução tecnológica em constante avanço, muitas dessas tecnologias facilitam a vida das pessoas no que se refere ao acesso à informação. Porém, se por um lado, pensadores como Manuel Castells (2016) sugerem que a sociedade está vivenciando a chamada sociedade do conhecimento globalizado, por outro, autores como Duarte (2008) alertam que isso é uma ilusão e um engano, pois todo esse avanço constitui uma disseminação da informação, mas não de conhecimento para todos.

Dessa contradição, que é teórica e social, nascem debates acadêmicos e mitos do senso comum. De nossa parte, no presente artigo, destacamos um debate que é acadêmico e que produz eco no senso comum do fazer educacional: o uso pedagógico de Tecnologias Emergentes (TE) por professores da Educação Básica. São inúmeras as pesquisas que enaltecem o potencial pedagógico dessas tecnologias. Não discordamos dessa hipótese, mas defendemos o papel fundamental do professor em selecionar quais tecnologias utilizar e que informações melhores colaboram para a apropriação do conteúdo científico (VYGOTSKI, 1934/1982; DAVYDOV, 1988), do saber sistematizado (SAVIANI, 2014; DUARTE, 2001), por seus estudantes. 
Devemos nos questionar: o quão exitoso é o nosso processo de formação docente para o trabalho pedagógico com tecnologias emergentes nas escolas? Qual a estrutura tecnológica das nossas escolas públicas? O quão eficaz é a formação continuada que ofertamos a nossos professores com vistas ao uso pedagógico dessas tecnologias? Quais as condições materiais que dispõem nossos estudantes?

Adotamos perspectiva teórica que vincula o desenvolvimento humano à educação escolar, o que é defendido por estudiosos como Vygotsky(i) (1934/1982; 1931/1995; 1925/1991), Saviani (2009; 2014), Duarte (2001; 2008), Martins (2016), Castro (2014), Leontiev (1978) e Davydov (1988), para citar alguns.

Um dos desafios posto às escolas é promover um espaço crítico para o uso das TE pelos docentes e para a aprendizagem dos educandos por meio dessas tecnologias e, assim, reconhecer sua relevância nos modos de ser e de agir dos indivíduos no cotidiano, bem como o seu potencial didáticopedagógico (MORAN, MASETTO e BEHRENS, 2010; KENSKI, 2013; CASTRO, 2020). E ainda há um longo caminho para superarmos esse desafio nas escolas públicas de Porto Velho.

Diante desse contexto de contradições e desafios, a partir do conceito de mediação de Vygotski (1931/1995), consideramos os conteúdos científicos como mediadores do desenvolvimento cognitivo e as TE como instrumentos de mediação do processo educativo: educador - conteúdo científico educando. Entendemos que a escola necessita acompanhar os avanços tecnológicos da sociedade, sendo a abordagem deste tema de fundamental relevância, haja vista as preocupações diárias dos professores ao vislumbrarem as possibilidades de um trabalho que possibilite maior acesso ao conhecimento científico e mais entusiasmo pelos estudantes. Preocupações vivenciadas e compartilhadas em escolas do município de Porto velho e que nos motivaram a realizar este estudo.

No intuito de melhor compreender essa problemática, objetivamos investigar as percepções de licenciandos concluintes de um curso de Pedagogia e de professoras que atuam em escolas públicas de Porto Velho sobre limites e possibilidades do uso pedagógico das TE típicas das duas primeiras décadas do século XXI. Aos primeiros, focalizamos a pesquisa no processo formativo para o uso dessas tecnologias e, às últimas, em suas opções didático-pedagógicas e nas condições materiais para a efetiva utilização desses recursos em sala de aula. Para tal, baseamo-nos, ao longo do texto, em autores vinculados à Teoria Histórico-Cultural e à Pedagogia Histórico-Crítica, além de pesquisadores que tratam da relação educação-tecnologiai. Neste recorte da pesquisa acima referida, discutimos somente sobre os achados relativos às entrevistas realizadas com professoras atuantes em duas escolas do município de Porto Velho, capital do estado de Rondônia, Amazônia Ocidental brasileira.

A presente escrita está organizada da seguinte forma: Introdução; discussão acerca do uso pedagógico de Tecnologias Emergentes; descrição do percurso metodológico da pesquisa; problematização dos achados da análise dos dados e, por fim; nossas Considerações finais.

\section{AS TECNOLOGIAS EMERGENTES E AS PRÁTICAS PEDAGÓGICAS}

Castro (2020) explica que o conceito de Tecnologias Emergentes vem sendo utilizado na literatura acadêmica recentemente e foi adotado nos estudos vinculados ao Grupo de Pesquisa "HISTCULT Educação, Psicologia Educacional e Processos Formativos", da Universidade Federal de Rondônia (UNIR), essencialmente, por seu caráter atemporal e por superar outras conceituações, como Novas Tecnologias da Informação e Comunicação (NTIC), Tecnologias da Informação e da Comunicação 
(TIC) e Tecnologias Digitais Virtuais (TDV). Defendemos que uma tecnologia será emergente em seu tempo e será nova somente naquele tempo. Além disso, as tecnologias típicas da segunda década do século XXI possuem características que vão muito além de informar e comunicar. Os usuários de smartphones conectados podem realizar uma série quase inimaginável no século XX de atividades com um aparelho que cabe na palma da mão. Castro (2020) salienta que muitas dessas atividades levam ao encontro o virtual e o real, em tempos variáveis, espaços distintos, multimodais e multimídias.

As TE estão corporalmente presentes no ambiente físico, na casa, no trabalho, estão em praticamente todos os ambientes, lendo os signos que mediam as relações sociais (VYGOTSKI, 1931/1995) sem interrupção. Umas das discussões que temos realizado desde meados da década de 1990 está relacionada à incorporação de TE (em seu determinado período histórico) pela Educação. Muitas pesquisas vêm sendo realizadas no Brasil enaltecendo o potencial pedagógico dessas tecnologias.

Em um estudo longitudinal realizado por Damiani et al. (2016), foram apresentados resultados positivos em relação à aprendizagem escolar dos educandos que possuíam computadores em suas casas:

Esse trabalho mostrou que o uso do computador esteve positivamente associado à diminuição da reprovação nos participantes da "Coorte de Nascimentos de Pelotas, 1993", tanto em análises brutas, quanto na maior parte das análises multivariadas, corroborando os resultados de outras pesquisas brasileiras e estrangeiras. As análises brutas mostraram que o uso aos 11 anos foi o que se mostrou mais relevante, associando-se à diminuição das taxas de reprovação. Em que pese os resultados encontrados nesta pesquisa, pensa-se ser importante frisar que o uso do computador no domićlio, mesmo sendo identificado como positivo, não pode ser considerado como solução para o enfrentamento do fracasso escolar, o fracasso escolar é um fenômeno multideterminado e bastante complexo. Os resultados positivos, no entanto, sugerem que o tema aqui enfocado deve continuar a ser pesquisado, incluindo estudos qualitativos ou quantitativos experimentais que possam explorar os processos envolvidos nessa complexa relação entre o uso doméstico de computador e o desempenho escolar. Esses resultados sugerem, da mesma forma, a necessidade de que os professores promovam o uso adequado desses equipamentos, entre os alunos, cultuando-os a essa tecnologia, de modo que tal uso possa contribuir para diminuir os altos índices de reprovação, que prevalecem em nosso país, entre crianças e adolescentes (DAMIANI et al., 2016 p., 76).

Com o passar dos anos, o computador deixou de ser o instrumento tecnológico mais utilizados pelas famílias e entre as pessoas. Os dispositivos móveis, típicos da segunda década do século XXI, estão nas mãos de praticamente todas as pessoas, o que facilita o acesso à informação e corrobora com as perspectivas suscitadas pela pesquisa de Damiani et al. (2016) sobre a importância da posse e do uso desses instrumentos - guardando as proporções entre o uso de um computador e de uma tecnologia móvel e a gradual superação do primeiro pela segunda.

A escola se destaca como o lugar propício à apropriação do saber sistematizado (SAVIANI, 2009; DUARTE, 2001), considerando o conhecimento espontâneo (VYGOTSKY, 1934/1982) dos estudantes como ponto de partida para o trabalho pedagógico dos conteúdos. Nessa condição, a prática educativa com o uso das TE como instrumentos de mediação auxilia na apropriação do universo simbólico disponibilizado de forma estruturada aos educandos. Diante dessas considerações, discutir sobre a utilização das TE como instrumento de mediação nas escolas, para além de uma visão meramente tecnicista, faz-se necessário e urgente. Pesquisas que abordam a utilização das TE como potencializadoras da aprendizagem dos educandos são relevantes para que haja entendimento sobre 
como essas tecnologias estão sendo inseridas nas escolas e qual está sendo o seu uso pedagógico pelos professores que as universidades estão formando.

Para além dessa problemática dos artefatos instrumentais, é preciso também destacar que, o que se vê na prática escolar, nas escolas que já utilizam algum equipamento tecnológico emergente, é que, apesar deles, pouca coisa se alterou no processo de ensino. Para Kenski (2012), é necessário que todos estejam conscientes e preparados para assumir novas perspectivas filosóficas que contemplem visões inovadoras de ensino e de escola, aproveitando-se das amplas possibilidades comunicativas e interacionais propiciadas pelas novas tecnologias para a concretização de um ensino crítico, transformador, de boa qualidade e não excludente.

O processo do conhecimento está nas culturas material e intelectual produzidas pela humanidade (LEONTIEV, 1978). As transformações históricas e sociais humanas são bem visíveis em nossa sociedade na transformação dos instrumentos de comunicação, ou seja, no jeito de se comunicar, não diferente do processo que ocorreu com o avanço da escrita cuneiforme pelos sumérios na antiga Mesopotâmia (atual Iraque), e, posteriormente, no século XV, na Alemanha, com a imprensa de Gutemberg (KENSKI, 2007).

Como difusora da cultura, a escola deve ter a compreensão dessa concepção filosófica que distingue as TE do simples modismo e se apropriar dessas ferramentas de forma crítica, como mediadoras dos processos educativos. A circulação de uma cultura de empoderamento do saber sistematizado entre os indivíduos e os grupos sociais não é arbitrária, é necessária. É imprescindível uma Educação que promova o desenvolvimento cognitivo de forma a não excluir parte da população: que em todas as escolas sejam proporcionadas as possibilidades de apropriação da cultura e do saber erudito, do conhecimento sistematizado, por seus aprendentes. Esse pensamento encontra eco nos fundamentos teóricos e epistemológicos da Teoria Histórico-cultural e da Pedagogia Histórico-crítica "(...) que não são indiferentes à análise das condições objetivas que, em uma sociedade de classes, reservam para diferentes indivíduos condições desiguais de humanização" (MARTINS, 2013, p. 272). Para além da análise das condições objetivas, tais perspectivas teóricas e epistemológicas se contrapõem às formas desiguais de desenvolvimento que a sociedade capitalista determina aos indivíduos.

Nessa direção, cabe destacar que a cultura globalizada e o acesso direto às informações via internet, mediante o uso das tecnologias móveis, não garante ao estudante a possibilidade de alcançar conhecimento sozinho, pois este é construído pelo aprendiz através do processo de transformação da informação, que exige formação, pensamento lógico, raciocínio e criticidade. Para isso, é necessária a mediação pedagógica do professor e destacada a centralidade da escola nesse processo, pois informação não equivale a conhecimento. $E$ a inserção do uso das TE nas escolas, em meio à revolução tecnológica, não deve estar a serviço dos interesses do mercado, sem uma preocupação do seu investimento como recurso pedagógico capaz de mediar o conhecimento sistematizado. Esse tipo de intenção não interessa a professores e estudantes das escolas públicas, brasileiras e rondonienses, pois não atende ao que se propõe para uma Educação universal e equânime.

Contudo, o desenvolvimento tecnológico impõe às escolas a necessidade de desenvolver novas habilidades e/ou potencializar nas crianças os referenciais do mundo digital. Diante da realidade social atual, e especificamente sobre o uso da internet, seja ela estática ou móvel, para Moran, Masetto e Behrens (2010), 
aula convencional. A internet também pode ser utilizada na sala de aula, conectada só pelo professor, como tecnologia complementar, ou pode ser utilizada também pelos alunos conectados através de notebooks na mesma sala de aula, sem deslocamento (MORAN, MASETTO E BEHRENS, 2010, p.51).

Como usuários da internet, os educandos devem ser orientados, desde a tenra idade, a uma postura de investigação e autonomia, a estarem aptos a superar problemas concretos do cotidiano. Assim, mais do que decorar conteúdos, nossos estudantes precisam aprender a acessá-los, a pensar e a refletir sobre eles (MORAN, MASETTO e BEHRENS, 2010), pois a educação acontece também em outros espaços, e não somente nas instituições de ensino, conforme preconiza a Lei de Diretrizes e Bases da Educação Nacional, em seu artigo 10: "a educação abrange os processos formativos que se desenvolvem na vida familiar, na convivência humana, no trabalho, nas instituições de ensino e pesquisa, nos movimentos sociais e organizações da sociedade civil e nas manifestações culturais" (BRASIL, 1996).

Nesse contexto, há necessidade de a escola utilizar as TE a serviço da aprendizagem. Entre os aparelhos móveis, podemos destacar os tablets, os notebooks e, principalmente, os smartphones (telefones inteligentes). A escola, muitas vezes, não aceita o uso desses últimos, de forma contraditória ao fascínio que despertam em seus usuários. Esses dispositivos, além de móveis e versáteis, são multimodais: convergem jogos, estudos, trabalho, vídeos, fotos, música, textos, tudo ao mesmo tempo e mantendo relações de forma ubíqua com seus contatos via redes sociais e comunicadores instantâneos. Esses telefones inteligentes são dispositivos que vão muito além da simples comunicação oral.

Os dispositivos móveis conectados são fáceis de manusear em qualquer lugar. Através deles, temos acesso a informações em tempo real; ao mesmo tempo em que surge uma notícia, em qualquer esfera, conseguimos nos comunicar e, até mesmo, debater e levantar questionamentos e discussões acerca do que está acontecendo em diversas partes do mundo ou em pequenos grupos conectados por temáticas afins. Para Santaella (2013), a aprendizagem ubíqua se refere às novas formas de aprender mediadas pelos dispositivos móveis, porém, as condições propícias de conexão são as que afetam diretamente as formas de educar e aprender, pois tanto podem incluir como excluir.

O Centro Regional de Estudos para o Desenvolvimento da Sociedade da Informação (CETIC.BR, 2018) vem realizando pesquisas no Brasil sobre o uso das tecnologias em domicílios e na Educação. Em 2017, este estudo apontou que 50\% dos indivíduos conectados já acessavam à internet somente pelo celular. Essa pesquisa também apontou que a proporção de usuários vem crescendo exponencialmente, sendo, naquele ano, 120,7 milhões de brasileiros usuários de internet. 0 estudo também apontou a preferência para o acesso de conexão pelo celular, totalizando $96 \%$ entre as pessoas pesquisadas.

A pesquisa constatou, ainda, que já é maior o número de domicílios com celulares do que com computadores conectados (CETIC.BR, 2018). E, ao levarmos em consideração a conexão da internet nos celulares, a faixa etária de usuários que predomina é a dos jovens (CETIC.BR, 2018). Essa informação sugere maior facilidade quanto ao uso das TE nessa faixa etária pelo uso mais frequente. Redes sociais, canais do Youtube e as diversas páginas e grupos fechados predominantes na internet, geralmente, são moderados por eles e voltados para eles. Moran, Masetto e Behrens (2010) sustentam que a internet é uma mídia que facilita a motivação dos educandos e que essa motivação aumenta se o professor criar um clima de confiança, de abertura e de cordialidade com os aprendizes, 
pelo equilíbrio, pela competência e pela simpatia com que utilizam esse recurso, desenvolvendo novas formas de novas comunicações em prol da Educação.

Através da mediação pedagógica, as TE devem proporcionar aos educandos a possibilidade de vivenciar emoções e saberes, independente da sua cultura local ou de sua localização geográfica. Criamos e potencializamos novas formas de nos relacionarmos e com o mundo. $E$ as novas experiências advindas desses novos "espaços" de troca, através das redes sociais, comunicadores instantâneos e sites de interesse comum, podem contribuir para um melhor aprendizado e convivência, onde quer que estejam inseridos.

Nesse sentido, defendemos as possibilidades de utilização das TE como mediadoras da ação pedagógica escolar, entendendo que elas podem se constituir em instrumentos de mediação à apropriação dos conteúdos sistematizados e melhorar a qualidade da aprendizagem dos estudantes, contribuindo para seu desenvolvimento intelectual e sua consequente inclusão social. Entretanto, para que essa mediação através das TE aconteça, é importante que o professor entenda o como e o porquê de usar a tecnologia educacional. Esse processo, denominado no senso comum "alfabetização tecnológica", deve ser analisado enquanto processo histórico e, no caso do professor, não deve estar vinculado predominantemente a experiências cotidianas somente, mas a processos formativos, iniciais e continuados, baseados nas Ciências da Educação e em pressupostos didático-epistemológicos.

A introdução das TE na Educação não pretende resolver e/ou acabar com os problemas educativos, mas, como defende Libâneo (2013), a escola desejada é aquela que assegura a todos a formação cultural e científica para a vida pessoal, profissional e cidadã, numa relação de aprendizado que desenvolva a autonomia e a crítica, numa formação completa, em suas várias manifestações: pela ciência, pela técnica, pela ética, pela cultura paralela dos meios de comunicação de massa e pela cultura local cotidiana.

Corroboramos o posicionamento de Libâneo e entendemos que, para avançarmos em termos de uso pedagógico das $\mathrm{TE}$, nas escolas públicas brasileiras e rondonienses, precisamos de processos formativos condizentes com a realidade tecnológica emergente de nosso tempo. Na sequência, descrevemos, em formato de síntese, o percurso metodológico da investigação empreendida e seus resultados, com o objetivo de acrescentar elementos a essa importante discussão, a partir das percepções das professoras que participaram da pesquisa.

\section{PERCURSO METODOLÓGICO INVESTIGATIVO}

Diante do contexto acima problematizado, foi realizada pesquisaii iii, de abordagem qualitativa e do tipo exploratória (BAUER e GASKELL, 2017; GIL, 2010), que objetivou investigar as percepções de formandos de um curso de pedagogia e de professoras de escolas públicas de Porto Velho sobre 0 uso pedagógico de tecnologias emergentes na prática pedagógica.

Neste recorte ${ }^{i v}$, são apresentados e discutidos somente os resultados relativos às percepções das professoras de duas escolas municipais, denominadas Escola A e Escola B $\mathrm{B}^{\vee}$. O critério de seleção das escolas foi: uma escola que alcançou a meta mínima 6,0, estabelecida para o IDEB do ano de 2017 (Escola A (IDEB 6,1), localizada no Centro de Porto Velho) e que autorizou a realização da pesquisa junto a seus docentes; e uma que não atingiu a meta do IDEB nesse mesmo ano (Escola B (IDEB $5,4)$, localizada na Zona Leste do município) e que também aceitou que seus docentes participassem do estudo. 
Porto Velho, capital do estado de Rondônia, que integra a Amazônia Ocidental brasileiravi, possui $34.096,338$ Km² de área geográfica, com uma população de 529.544 pessoas, sendo o mais populoso de Rondônia e o quarto mais populoso da Região Norte do país. É a capital brasileira com maior área territorial, com mais de 34 mil km² - mais extenso do que países como Bélgica e Israel (IBGE, 2019). Porto Velho possui 232 escolas, com 3138 docentes atuantes no Ensino Fundamental (EF), alcançando Índice de Desenvolvimento da Educação Básica (IDEB) médio de 5,3 nos Anos Iniciais do EF (IBGE, 2019).

Os critérios de inclusão das participantes foram: ser professor dos anos iniciais (10 ao $5^{\circ}$ ano) do Ensino Fundamental de uma das duas escolas selecionadas e aceitar participar da pesquisa. Os critérios de exclusão foram: estar ausente nos dias agendados para a realização das entrevistas, estar em férias, estar em licença e/ou não aceitar participar da pesquisa. Foram entrevistadas, no total, doze professoras, todas do sexo feminino, sendo seis em cada escola. Para a coleta de dados, foi realizada entrevista do tipo semiestruturada (GIL, 2010), constituída por dez questões, sendo quatro fechadas e seis abertas, realizada entre junho e agosto de 2018.

De acordo com os dados levantados pela investigação empreendida, das professoras da Escola A, $100 \%$ utilizam o computador conectado à internet e $83 \%$ utilizam o celular conectado. Entre as professoras da escola $B$, apenas $50 \%$ fazem uso do computador em seu dia-a-dia e $100 \%$ delas utilizam o celular conectado à internet diariamente. A predominância do uso do smartphone conectado vai ao encontro dos apontamentos de Santaella (2013) e Castro (2020) sobre as vantagens do uso de tecnologias móveis e sobre o quanto esses artefatos culturais estão presente na vida dos brasileiros. No que tange às redes sociais utilizadas pelos educadores, $83 \%$ das professoras da escola A e a mesma porcentagem na escola B usam o YouTube como principal rede social. Verificou-se, também, que, na Escola A, o segundo aplicativo mais utilizado é o Instagram e, na Escola B, o Facebook.

A Análise Textual Discursiva foi a técnica adotada para a análise dos dados, que foram organizados, sistematizados e analisados nos moldes preconizados por Moraes (2003). Esse tipo de análise se divide em quatro etapas: (1) desmontagem; (2) estabelecimento de relações, categorização; (3) captação do novo emergente e; (4) processo auto-organizado final. Primeiramente, foi realizada a desconstrução dos dados obtidos a partir das repostas das falas da entrevista com as doze professoras em exercício na Rede Municipal de Ensino de Porto Velho, direcionando-os para o corpus da pesquisa.

Na segunda etapa, foi realizada nova e cuidadosa leitura do material da pesquisa e elaborada a categorização das informações oriundas das respostas das professoras a partir de unidades significativas emergentes (MORAES, 2003). Foram definidas, e serão aqui discutidas (em formato de síntese, devido às limitações de espaço), as seguintes categorias de análise: a) Percepções sobre a formação para o uso das TE; b) Percepções sobre a importância da base teórico-prática para a prática pedagógica e; c) Percepções sobre limites e possibilidades do uso das TE na prática pedagógica.

Apresentadas as categorias, passamos à captação do novo emergente e à construção do texto, agora, com as inferências dos pesquisadores, mas sem modificar a realidade inicial dos dados. A materialização dos elementos apresentados a seguir implica em um movimento de afastamento do material empírico, de maneira a expressar novas compreensões (MORAES, 2003; BAUER e GASKELL, 2017). 


\section{PERCEPÇÕES DAS PROFESSORAS SOBRE O USO PEDAGÓGICO DAS TECNOLOGIAS EMERGENTES}

A seguir, apresentamos e discutimos os dados analisados, cumprindo a sequência preconizada por Moraes (2003).

\section{a) Percepções sobre a formação para o uso das TE}

Os dados acerca da percepção das professoras sobre a formação para o uso das TE em práticas pedagógicas se originam das questões cinco e seis da entrevista semiestruturada. Na questão cinco da entrevista, perguntamos: "Você utiliza as tecnologias emergentes em sua prática pedagógica?"

Os resultados obtidos junto às professoras da Escola $A$ indicaram que $100 \%$ referiram utilizar alguma tecnologia. Resultado destoante dos da Escola $B$, entre as quais apenas $33 \%$ manifestaram utilizar e expressivos $67 \%$ afirmaram não utilizar as TE em suas práticas pedagógicas.

No concernente à percepção acerca do sentimento de preparo para a prática pedagógica com o uso de TE, baseamo-nos na questão seis da entrevista, na qual perguntamos: "Você se sente preparada para utilizar as tecnologias em sala de aula?'.

As percepções apreendidas nas respostas das professoras revelaram que $83 \%$ das professoras da escola $A$ se sentem preparadas para o uso pedagógico das $T E$, enquanto $50 \%$ das professoras da Escola B comungam desse sentimento. Ou seja, ao final da segunda década do século XXI, 33,5\% (17\% na Escola A e 50\% na Escola B) das professoras entrevistadas não se sentem preparadas para o uso das TE em suas práticas. Esses dados revelam a lacuna apontada por Castro (2020) em sua pesquisa acerca dos currículos dos cursos de Pedagogia das universidades federais da Região Norte do Brasil, entre os quais, dois sequer oferecem uma disciplina obrigatória direcionada ao trabalho didático de tecnologias na Educação em sua grade de disciplinas. Os dados também revelaram que $17 \%$ das professoras da Escola A utilizam TE em suas práticas mesmo sem se sentirem efetivamente preparadas para tal.

A percepção sobre o sentimento de preparo para o uso das TE na prática docente pode vir do seu uso no cotidiano, do espontaneísmo pedagógico, pois o uso de meios tecnológicos está naturalizado entre as pessoas, principalmente, o uso de smartphones conectados a redes móveis. As principais vantagens do uso do smartphone conectado, que é um sistema multimodal, de comunicação ubíqua e para leitores ubíquos, residem na praticidade de seu uso e no fácil acesso a informações diversificadas e a recursos variados, como aplicativos educacionais, redes sociais e canais do YouTube, além de ferramentas para a realização de pesquisas.

O sentimento de "preparo" fica explícito na fala de duas professoras da Escola A, instituição na qual a grande maioria das professoras manifesta estar preparada para o uso pedagógico das tecnologias, mesmo que se trate de uma "formação continuada" forjada pelo dia-a-dia e não algo relacionado a um processo formativo institucional, conforme os depoimentos a seguir:

Sim, por autonomia, não pela escola. (P1, Escola A)

Com relação ao manuseio, eu me considero preparada, porém com relação à sala de aula é complicado, uma vez que em sala, você tem que preparar todo o equipamento para poder fazer uso. Há uma perda de tempo (aula) na montagem desses recursos. (P4, Escola A) 
Entre as professoras que se sentem preparadas para o uso pedagógico das $T E$, há aquelas que consideram esse preparo um esforço próprio ou parte de sua autonomia - estar "preparada" significa saber montar o equipamento, no sentido de conseguir manusear os recursos. E esse "preparo", segundo nossas observações em escolas de Porto Velho, estará condicionado à disponibilidade de uma sala já montada com os equipamentos multimídia, devidamente habilitados, o que acontece pouco na rede de Educação Básica do município. Outras se consideram preparadas no caso de haver internet na escola que suporte executar vídeos do YouTube, por exemplo; já outras se sentem preparadas, mas não fazem uso das TE - contexto que está muito distante de um uso pedagógico de tecnologias móveis, de aprendizagem ubíqua ou de educação híbrida (CASTRO, 2020), para mencionar somente as possibilidades emergentes mais usuais.

Entre as professoras que não se sentem preparadas, algumas relatam ser em razão da carência de estudos específicos e/ou por não saberem manusear os equipamentos, como montagem e desmontagem de um periférico ou de um recurso multimídia. Percebemos, claramente, neste ponto das entrevistas, o sentimento de falta de formação inicial e continuada para esse tipo de prática pedagógica entre as professoras entrevistadas das duas escolas.

Nas palavras de Kenski (2007), os professores não são formados para o uso pedagógico das tecnologias, sobretudo, das TE, como salienta Castro (2020). Aliados aos problemas técnicos e operacionais da falta de estrutura física há, também, as lacunas da própria profissionalização do professor. Kenski (2007) ainda sinaliza que a diferença da prática não está no uso ou não uso das $T E$, mas na compreensão das possibilidades desses instrumentos como potencializadores das suas práticas pedagógicas. As professoras participantes da pesquisa percebem que há possibilidades de as tecnologias ajudarem em suas práticas e, consequentemente, à compreensão dos conceitos científicos por seus estudantes. No entanto, pouco ou nada utilizam em suas possibilidades mais emergentes e ricas em diversidade didática.

Analisar essa situação implica considerar o que Martins (2016) relata sobre o desenvolvimento do indivíduo, que se dá nas transformações condicionadas pelo trabalho ou atividade que sustenta o entorno físico e social. Nesse sentido, a Educação Escolar é um fator decisivo na humanização do psiquismo e para atos voluntários da consciência (VYGOTSKI, 1925/1991). A diversidade didática é, nesse sentido, fundamental para as aprendizagens e ao desenvolvimento cognitivo dos estudantes.

\section{b) Percepções sobre a importância da base teórica para a prática pedagógica}

Essa categoria apresenta os dilemas e os desafios que a formação inicial enfrenta quanto aos modelos de formação dualista, um pautado na prática e outro na teoria; e as implicações dessa formação inicial no embasamento das práticas educativas desenvolvidas pelas professoras em sala de aula. $\mathrm{A}$ seguir, apresentamos um resumo das percepções das professoras sobre a importância da base teórico-prática para sua atuação pedagógica na escola, com base na questão sete da entrevista: "Você utiliza alguma base teórico-prática da sua formação inicial em Pedagogia?".

As professoras da Escola $\mathrm{A}$ afirmaram não utilizarem nenhuma base teórico-prática oriundas de sua formação inicial. Destacamos, abaixo, as falas de P1A e P2A:

Não, nós não temos uma formação adequada para atuar nesta questão. Geralmente na graduação de Pedagogia não é trabalhado com tanto afinco o assunto dessas tecnologias. Eu conheço bem as Tecnologias educacionais e as exerço porque gosto, por acreditar na eficácia de seu uso. Não saí da faculdade com a aptidão necessária para utilizar as tecnologias. (P1, Escola $A$ ) 
Sinceramente, não. O curso de Pedagogia possui muita base teórica, com fundamentos e princípios conceituais, porém, o desafio começa a acontecer na prática. Muita teoria que é aprofundada na graduação não é utilizada na prática, pois a realidade na sala de aula é totalmente diferente e subjetiva. (P2, Escola A)

P1A se formou no ano de 2014, em uma instituição de ensino particular, e declara que não teve uma formação específica relacionada ao uso didático de tecnologias na Educação, revelando a percepção de que deixou a faculdade sem obter a capacitação necessária para fazer o uso pedagógico das TE, mas, que, apesar disso, aprecia-as e as utiliza, enfatizando que aprendeu de forma autônoma, desvinculada de uma teoria que a sustentasse. A professora P2A relatou que houve aprofundamento teórico em sua formação, porém, desvinculada da prática de sala de aula.

A percepção geral que tivemos em relação às percepções das professoras da Escola A sobre sua formação é a de que a teoria não condiz com a realidade da instituição onde atuam. Das seis professoras entrevistadas, quatro afirmaram que não utilizam qualquer base teórica em suas práticas pedagógicas.

Na Escola B, das seis professoras, apenas uma (P2B) afirmou fazer uso do embasamento teórico de sua formação em suas práticas pedagógicas:

Sim, frequentemente eu consulto os autores, pois uma prática pedagógica sem teoria e fundamentação é viver no senso comum, então, sempre que procuro embasar as práticas educativas através das fundamentações teóricas, nas questões dos níveis, das teorias que corroboram com a alfabetização. (P2, Escola B)

Percebe-se, na fala de P2B, a relevância do tempo dispendido ao estudo para uma melhor preparação de sua condição como educadora. Ainda que as professoras entrevistadas sejam graduadas em nível superior, e algumas com formação de pós-graduação Lato sensu, a professora P2B era a única, entre todas as doze entrevistadas, com pós-graduação Stricto sensu em nível de Doutorado. Mais anos de estudo constituíram uma educadora consciente da importância de uma docência crítica, baseada em pressupostos teóricos que ampliem seu repertório de possibilidades didáticas e sua visão de mundo frente às contradições teóricas e sociais da Educação contemporânea.

Ao analisar a percepção desta professora da Escola B, e das outras duas da Escola A, sobre a importância da teórico-prática em suas formações, Leontiev (1978) nos ajuda a compreender que o processo de formação se dá ao longo de vida e que a relação dialética entre os fatores externos e internos à escola é o que possibilita as condições para que haja apropriação do conhecimento e desenvolvimento intelectual e profissional, caracterizados pela formação de novas capacidades e funções cognitivas produzidas pela atividade social do indivíduo em um processo contínuo (CASTRO, 2014; MARTINS, 2016), para professores e estudantes.

A característica essencial da apropriação do conhecimento é que ela não acontece de uma maneira passiva do indivíduo frente à realidade, assim, a formação do pensamento teórico-prático passa a ser a finalidade principal da Educação também para os educadores. Leontiev (1978) já destacava que o processo de formação de funções psicológicas superiores acontece mediante condições favoráveis à atividade e à escolarização, o que exige organização de objetivos e escolhas metodológicas.

$\mathrm{Na}$ análise das duas escolas, verificamos o tempo passado desde a última formação institucional como fator de desvinculação da teoria ora estudada das práticas pedagógicas, conforme ilustram as falas das professoras P4B e P3A: 
Não. Já faz nove anos que eu me formei. (P3, Escola A)

Tais percepções de desconsideração da teoria para o embasamento das práticas acabam comprometendo ainda mais a atuação dessas professoras, pois operam como fator de desestímulo à procura por cursos de formação continuada e à dedicação aos estudos (SAVIANI, 2009). Nove das doze educadoras entrevistadas admitem não utilizarem nenhuma teoria da Educação em sua prática pedagógica. Algumas delas afirmaram, ainda, que o curso de Pedagogia utiliza muita teoria e que, quando concluem a graduação e assumem a sala de aula, abandonam os conceitos e focam apenas na prática - como se teoria e prática estivessem dissociadas. Isso reforça discursos de que as teorias educacionais não estão sintonizadas com as práticas nas escolas, reforçando a dualidade teoriaprática.

Constatamos que as professoras não percebem (ou não se importam com) a relevância das teorias educacionais para suas práticas. No entanto, qualquer a atividade pedagógica está fundamentada sobre uma base teórica, mesmo que inconscientemente por parte do educador. Teoria e prática não devem estar dissociadas, mas essa relação deve ser dialética e mutuamente constitutiva, constituindo-se, efetivamente, pela unidade entre concepções teóricas e atividades práticas no interior das escolas.

Levando em consideração que a escola está imbricada às contradições de cada sociedade e, de certa forma, o papel do professor também se constitui dessas contradições, suas ações nunca são neutras e, certamente, as professoras têm certo discernimento de como ocorre o ensino por elas praticado e sobre as aprendizagens de seus estudantes. E é essa percepção que irá orientar sua prática pedagógica. Inferimos, então, que as professoras entrevistadas, mesmo não sabendo definir exatamente qual teoria embasa suas práticas, ou estando inclinadas a não referenciarem teoricamente atuação, estão sob a influência de algum paradigma educacional, mesmo que seja aquele que atribui à prática espontaneísta do professor o protagonismo da ação docente.

\section{c) Percepções sobre as possibilidades de uso das TE na prática pedagógica}

A presente categoria revela as contradições existentes entre a realidade da sociedade e a vivenciada pela escola (fruto desta primeira) e as possibilidade de uso pedagógico das TC no contexto de atuação das professoras entrevistadas.

A análise dessa categoria emergiu da questão oito da entrevista, que assim versava: "Quais recursos tecnológicos você utiliza em sala de aula?". As professoras da Escola A assim se manifestaram:

Quando eu trago os recursos de casa, utilizo data show, notebook, HD externo, caixinha de som para usar a música, e às vezes, uso a televisão da escola (P1).

Meu notebook, quando necessário, meu celular e a televisão. Eu uso muito vídeos em sala de aula, além do livro, além das atividades em folha de papel, eu trabalho os conteúdos em vídeos (P2).

Uso com muita frequência o Data Show, televisão e, às vezes, o celular. Acontece também de ter o questionamento de algum aluno, caso eu não saiba responder, pesquiso e Ihes dou a resposta na hora, se possível, mostro áudio ou imagens. Eu uso a minha internet e a da escola, porque às vezes a da escola não dá suporte (P4).

Eu uso de maneira muito frequente o meu notebook, eu faço o download dos vídeos em casa e repasso na sala de aula para os meus alunos. (P6) 
Os depoimentos das quatro professoras da Escola A deixam claro que todas acabam tendo que usar ferramentas e recursos próprios para conseguirem utilizar pedagogicamente as tecnologias. Ainda assim, apenas P2A menciona o celular como um recurso a ser utilizado junto aos estudantes, revelando, mais uma vez, o distanciamento dos professores da Educação Básica das tecnologias emergentes típicas do século XXI, indo ao encontro do que fora "denunciado" por Castro (2020). As falas acima também revelam a precariedade das escolas em termos de instrumentos e de conexão de internet, destacando o uso exacerbado dos aparelhos e dispositivos pessoais pelas docentes, como celulares e notebooks.

Também cabe reforçar que o uso de vídeos e livros audiovisuais, ou o trabalho com filmes de conteúdo didático explicativo, ilustrativo à cada disciplina, depende da disponibilidade de conexão de internet que dê suporte à execução do aplicativo/programa a ser utilizado, bem como de uma televisão adequada, ou data show, e que haja compatibilidade com os aparelhos celulares de professores e estudantes, diminuindo o complicador do tempo gasto em montar os aparelhos multimídias em aulas de, no geral, 45 minutos.

Cabe o destaque, aqui, das percepções das professoras a respeito da desatualização escolar em termos de estrutura para o uso das tecnologias emergentes típicas do século XXI, escolas pouco inseridas na propalada "sociedade do conhecimento" (CASTELLS, 2016). Segundo o que pudemos perceber, tanto na pesquisa realizada nessas duas escolas, como em nossa atuação supervisionando estágios em mais de 40 escolas de Porto Velho, e em outras pesquisas, que, talvez, não estejamos falando nem mesmo de uma "sociedade da informação", corroborando as críticas de Kenski (2007), Duarte (2008) e Saviani (2009).

Em nossa pesquisa, 100\% das professoras afirmaram que as escolas possuem laboratório. Todavia, verificamos, com base nas entrevistas, que os laboratórios das duas escolas não funcionam corretamente. Elas afirmaram que os computadores são "arcaicos e desatualizados", além de mencionarem a carência de pessoal especializado para sua manutenção ou de um coordenador desse espaço. Nas considerações de Kenski (2007), os principais problemas enfrentados com a utilização das TE como instrumentos de mediação nas escolas são o sucateamento dos computadores já adquiridos e os relativos à conexão de internet (ou a sua falta), pois "as escolas não têm verba suficiente para manutenção e atualização permanente dos programas e a realização de treinamentos para todo pessoal pedagógico e administrativo" (p. 59). Sobre essa realidade, Moran, Masetto e Behrens (2010) colaboram no sentido de enfatizar a importância de salas de aulas conectadas à internet e laboratórios bem equipados se quisermos, efetivamente, promover o manuseio de dispositivos que possibilitem aulas mais dinâmicas e com maior interatividade, facilitando a mediação entre os pares.

Sobre as possibilidades de uso das TE, as maiores dificuldades percebidas nas falas das professoras da Escola B são de origem técnica e de falta de formação/orientação:

Sim, para manusear não teria nenhuma dificuldade, mas não tenho acesso a estes recursos [...] eu sei manusear várias ferramentas sem nenhuma dificuldade. Há ainda a questão das tomadas, acho que contabilizando são três salas sem tomadas funcionado. (P2)

Não, devido à falta de conhecimento de como instalar corretamente um data show ao notebook, mas, infelizmente, pela falta de orientação, entende? Porque sou o tipo de pessoa que aprende fácil. (P3) 
Não, porque preciso de qualificação para poder manusear esses dispositivos corretamente, e poder usar dentro de uma sala de aula. Sempre que preciso fazer uso do data show eu preciso de ajuda para montá-/o. (P6)

P3B e P6B ilustram dificuldades sobre o manuseio de instrumentos básicos, como montar um data show ou um notebook, ficando evidente que precisam de formação continuada nessa área. São professoras que compreendem a necessidade de orientações básicas para aprender a executar esses aparelhos tecnológicos, o que é plausível, uma vez que somente a nova geração tem facilidade para utilizar esses recursos - segundo elas próprias. As dificuldades mudam de nuance na declaração da professora P2B, que enfatiza diversas dificuldades para o uso das TE, sendo, a maior delas, a simples disponibilização dessas tecnologias pela escola. Castro (2020), Kenski (2013), Moran, Masetto e Behrens (2010) sublinham que o grande desafio posto às escolas é promover um espaço formativo que esteja apto a fazer uso das $\mathrm{TE}$, indo ao encontro dos modos de ser e de agir dos indivíduos no cotidiano e reconhecendo seu potencial didático-pedagógico.

O que temos verificado em Porto Velho são, além da ausência de laboratório de informática em $61 \%$ das escolas do município (CENSO ESCOLAR, 2018), problemas básicos de infraestrutura, como, por exemplo, na instalação elétrica. P2B, apesar de ter disposição e certo conhecimento para usar pedagogicamente as $T E$, encontra-se impossibilitada de fazer uso desses recursos devido à ausência de tomadas nas salas de aula (!). Saviani (2009) enfatiza que a formação de docentes não pode ser pensada sem considerar as condições de trabalho propiciadas ao educador pelas instituições, pois as condições desfavoráveis - como jornada de trabalho, salários, estrutura física, recursos didáticos etc. - impossibilitam e neutralizam a ação dos professores, ainda que tenham participado de processos formativos que propiciem uma prática docente de boa qualidade e sintonizada com os avanços tecnológicos.

Saviani (2009) também declara que, tanto para garantir a formação do corpo docente de forma consistente, quanto para prover um ambiente escolar com estrutura adequada ao desenvolvimento do trabalho educacional, em que haja a possibilidade de uso de recursos mais modernos, é necessário o provimento de recursos financeiros, o que é, atualmente, mais um dos grandes desafios a serem enfrentados pela Educação Básica.

A Educação, desvinculada da sua prática social (entendendo-se, aqui, que os educandos das escolas pesquisadas estão inseridos em uma sociedade permeada pelas tecnologias típicas do século XXI), torna-se incoerente, pois a apropriação que se adquire do conhecimento produzido de forma histórica pela sociedade está condicionada às circunstâncias concretas em que vivem os indivíduos. 0 descompasso entre os avanços que ocorrem na sociedade e as práticas pedagógicas no interior da instituição educacional tem influência direta na educação escolar pública, o que prejudica a democratização do acesso ao conhecimento sistematizado pelas crianças das camadas mais desfavorecidas, geralmente, atendidas pelas escolas mais carentes de recursos e de infraestrutura tecnológica - nas palavras de Castro (2020), constituindo um loop de exclusão.

A consciência da concepção histórica do ser humano é fundamental para a promoção da aprendizagem e do desenvolvimento cognitivo de nossos estudantes, bem como a organização do saber científico, de forma sistematizada, e que a prática pedagógica aconteça de forma envolvente e comprometida para formar indivíduos em sua plenitude. 


\section{CONSIDERAÇÕES FINAIS}

A problemática abordada neste recorte da pesquisa realizada destaca um ponto de partida para possíveis debates que venham a contribuir com reflexões para que professores sejam sujeitos e não sujeitados às condições que lhes são impostas. As questões aqui abordadas investigaram a formação de professores para o uso pedagógico de Tecnologias Emergentes frente às exigências demandadas pela sociedade contemporânea, num contexto de transição imposto pelos avanços tecnológicos e pela necessidade de se promover Educação e emancipação humanas (SAVIANI, 2009; 2014).

Investigamos, diante desse contexto, percepções de professoras de duas escolas da Rede Municipal de Porto Velho acerca de suas práticas em sala de aula. Os achados apresentados foram analisados ressaltando suas percepções sobre limites e possibilidades de uso pedagógico das TE nas escolas de forma a problematizar: as relações com seus processos formativos; a dualidade entre teoria e prática e; as condições de trabalho, com ênfase na estrutura tecnológica nas escolas e na formação continuada para o uso das TE.

Com relação ao preparo para o trabalho pedagógico com as $\mathrm{TE}$, as professoras da Escola $\mathrm{A}$ (que alcançou o maior IDEB do município naquele ano) sentem-se mais preparadas do que as docentes da Escola B (que não atingiu a meta do IDEB para 2017). Quantos às percepções das doze professoras entrevistadas, materializadas em parte nas entrevistas que realizamos, relevaram: falta de embasamento teórico em suas práticas pedagógicas; descrédito à formação inicial recebida, consideradas por elas dissociadas da realidade das escolas em que atuam; dificuldades para trabalhar com as $T E$, que se originam na falta de preparo na hora de manusear certos equipamentos, mas, fundamentalmente, na falta de estrutura nas escolas para realizar trabalhos pedagógicos com as TE - como falta de espaço físico, computadores estragados, ultrapassados ou sem manutenção, instalações elétricas precárias nas salas de aulas e falta de internet. Verificamos, ainda, que as professoras que realizam trabalhos com tecnologias utilizam recursos e ferramentais pessoais - tendo em vista que os mesmos não estão disponíveis nas escolas.

Contudo, defendemos o potencial da utilização das TE na sala de aula como instrumentos de mediação dos conhecimentos sistematizados pelas professoras, com autonomia e criticidade, facilitando as aprendizagens dos milhões educandos nas escolas do país, incluindo aqueles residentes na Região Amazônica brasileira. Para isso, é necessário fortalecer os processos formativos (iniciais e continuados) dos profissionais docentes no sentido de propiciar formação sintonizada com os avanços tecnológicos típicos das duas primeiras décadas do século XXI e fornecer condições de trabalho nas escolas para que isso seja possível.

Entendemos que é necessário, também, conhecer a historicidade da constituição do professor (o que este artigo não daria conta de abordar), visando a compreensão do trabalho docente em toda a sua complexidade pedagógica, sociológica, filosófica e psicológica - na qual teoria e prática são inseparáveis, em uma prática educativa compromissada com a formação emancipatória humana.

Para finalizar, foi possível perceber que se faz urgente a construção de novos projetos, programas e políticas de formação, a fim de que sejam criados procedimentos que possam proporcionar perspectivas de desenvolvimento profissional aos professores, considerando-se as condições atuais voltadas à escola, propiciando uma nova transformação social sem prescindir dos avanços tecnológicos emergentes. 


\section{REFERÊNCIAS}

BAUER, Martin. W.; GASKELL, George. (Orgs.). Pesquisa Qualitativa com Texto, Imagem e Som: um manual prático. 6. ed. Petrópolis: Vozes, 2017. 516p.

BRASIL. Ministério de Educação e Cultura. LDB - Lei no 9394/96, de 20 de dezembro de 1996. Estabelece as diretrizes e bases da Educação Nacional. Brasília: MEC, 1996. Disponível em: <http://www.planalto.gov.br/ccivil_03/leis/19394.htm z. Acesso em: 05 maio. 2019.

CASTELLS, Manuel. A Era da Informação: Economia, sociedade e cultura. 5. ed. Lisboa: Fundação Calouste Gulbenkian, 2016. 713p.

CENSO ESCOLAR. INEP - Instituto Nacional de Estudos e Pesquisas Educacionais Anísio Teixeira. CENSO ESCOLAR. 2018. Disponível em: <http://portal.inep.gov.br/web/guest/censo-escolar >. Acesso em: 02 de jul. 2020.

CASTRO, Rafael F. de. A expressão escrita de acadêmicas de um curso de Pedagogia a distância: uma intervenção Histórico-Cultural. 2014. 238f. Tese (Doutorado) - Programa de PósGraduação em Educação. Universidade Federal de Pelotas, Pelotas.

CASTRO, Rafael F. de. Tecnologias Emergentes e Formação de Professores: o que as grades curriculares de cursos de Pedagogia sinalizam? In: Múltiplos Olhares sobre a Formação de Professores no Brasil. (Orgs.) SILVA, Marijâne S.; PEDROSA, Neide B.; ISOBE, Rogéria M. R. Porto Velho: EDUFRO, 2020.

CETIC.BR. Centro Regional de Estudos para o Desenvolvimento da Sociedade da Informação. Pesquisa e indicadores 2018. Disponível em: <https://cetic.br/pt/pesquisa/educacao/indicadores/>. Acesso em: 17 de mar. 2018.

DAMIANI, Magda Floriana et al. Afinal, o uso doméstico do computador está associado à diminuição da reprovação escolar? Resultados de um estudo longitudinal. Ensaio: aval. pol. públ. Educ., Rio de Janeiro, v. 24, n. 90, p. 59-81, jan./mar. 2016.

DAVYDOV, Vasily Vasilovich. La enseñanza escolar y el desarrollo psíquico. Havana: Editorial Progresso, 1988. 217p.

DUARTE, Newton. Vigotski e o "aprender a aprender": Crítica às Apropriações Neoliberais e Pósmodernas da Teoria Vigotskiana. 2. ed. São Paulo: Autores Associados, 2001. 269p.

DUARTE, Newton. Sociedade do Conhecimento ou das ilusões? Quatro ensaios críticosdialéticos em filosofia da educação. São Paulo: Autores Associados, 2008. 108p.

GIL, Antonio Carlos. Como elaborar projetos de pesquisa. 5. ed. São Paulo: Editora Atlas, 2010. 200p.

IBGE CIDADES. IBGE - Instituto Brasileiro de Geografia e Estatística. IBGE CIDADES. 2019. Disponível em: <https://cidades.ibge.gov.br/brasil/ro/porto-velho/>. Acesso em: 02 jul. 2020.

KENSKI, Vani Moreira. Educação e Tecnologia: o novo ritmo da educação. SP: Papirus, 2007. 144p. KENSKI, Vani Moreira. Tecnologias e Tempo Docente. SP: Papirus, 2013. 176p.

LEONTIEV, Alexis Nikolaevich. O desenvolvimento do psiquismo. Lisboa: Livros Horizonte, 1978. $356 p$. 
LIBÂNEO, José Carlos. Didática. 2. ed. SP: Cortez, 2013.

MARTINS, Lígia Márcia. 0 desenvolvimento do psiquismo e a educação escolar: Contribuições à luz da psicologia histórico-cultural e da pedagogia histórico-crítica. Campinas, SP: Autores Associados, 2013.

MARTINS, Lígia Márcia. Psicologia Histórico-cultural, Pedagogia Histórico-Crítica e Desenvolvimento Humano. In: MARTINS, Lígia Márcia; ABRANTES, Angelo Antonio; FACCI, Marilda G. Dias. (Orgs.). Priorização Histórico-Cultural do desenvolvimento psíquico: do nascimento à velhice. SP: Autores Associados, 2016.

MORAES, Roque. Uma tempestade de luz: a compreensão possibilitada pela análise textual discursiva. Ciência e educação, v. 9, n. 2, 191-2011, 2003.

MORAN, José Manuel; MO, Marilda Aparecida. Novas Tecnologias e Mediação Pedagógica. 21. ed. SP: Papirus Editora, 2010. 176p.

OLIVEIRA, Delziana de; CASTRO, Rafael F. de. Percepções de graduandas em Pedagogia sobre sua formação para o uso das Tecnologias Emergentes em sala de aula: um estudo de caso na Amazônia Ocidental. 2020. Revista Novas Tecnologias na Educação, v. 18, n. 1, p. 1-11, julho, 2020.

SANTAELLA, Lúcia. Comunicação ubíqua: Repercussões na cultura e na educação. São Paulo: PAULUS Editora, 2014. 304p.

SAVIANI, Dermeval. Formação de professores: aspectos históricos e teóricos do problema no contexto brasileiro. Revista Brasileira de Educação, v. 14, n. 40, p. 143-155, 2009.

SAVIANI, Dermeval. O lunar de Sepé: paixão, dilemas e perspectivas na educação. São Paulo: Autores Associados, 2014. 181p.

VYGOTSKI, Lev Semionovich. Obras Escogidas Tomo I (La consciencia como problema de la psicología del comportamiento). Madrid: Aprendizaje Visor y Ministerio de Educación y Ciencia, 1925/1991.

VYGOTSKI, Lev Semionovich. Obras Escogidas Tomo III (Historia del Desarrollo de las Funciones Psíquicas Superiores). Madri: Visor, 1931/1995. 383p.

VYGOTSKY, Lev Semionovich. Aprendizagem e desenvolvimento na idade escolar. In:Luria, Leontiev, Vigotsky. Psicologia e Pedagogia I: bases psicológicas da aprendizagem e do desenvolvimento. Lisboa: Editorial Estampa. p. 31-50, 1991.

VYGOTSKY, Lev Semionovich. Obras Escogidas Tomo II (Pensamiento Y Lenguaje). Moscú: Editorial Pedagógica, 1934/1982. 484p.

\footnotetext{
' Esta pesquisa integra o conjunto de investigações que compõem o Programa de Pesquisa Educação e Psicologia Histórico-Cultural: investigações teórico-práticas de processos educativos na Amazônia Ocidental (Portaria No 70/2019/PROPESQ/UNIR), vinculado ao Grupo de Pesquisa HISTCULT - Educação, Psicologia Educacional e Processos Formativos.

ii Todos os procedimentos para a execução da pesquisa a qual as informações mencionadas neste artigo se referem foram aprovados pelo CEP/UNIR/Plataforma Brasil, Parecer 2.989.963.

iii Esta pesquisa contou com o apoio da Coordenação de Aperfeiçoamento de Pessoal de Nível Superior (CAPES), mediante Bolsa de Pesquisa (2016-2018) concedida ao Programa de Pós-Graduação em Educação da Universidade Federal de Rondônia (UNIR).
} 
iv As discussões relativas aos resultados oriundos dos questionários aplicados aos formandos em Pedagogia estão publicadas em Oliveira e Castro (2020).

$\checkmark$ Nem os participantes e nem as escolas estão identificados por aspectos e questões de confidencialidade, de acordo com as resoluções mais atuais dos comitês de ética em pesquisa do Brasil.

vi Região constituída pelos Estados do Amazonas, Acre, Rondônia e Roraima, detém 42,97\% da extensão territorial da Amazônia Legal e comporta cerca de $57 \%$ das florestas da região, o que a torna a parte mais preservada da Amazônia brasileira, além de ser um estoque de biodiversidade sem igual no planeta. 